\title{
Nepenthes ultra (Nepenthaceae), a new species from Luzon, Philippines
}

\author{
M. Cheek ${ }^{1}$, M. Jebb²
}

\section{Key words}

conservation

Luzon

Nepenthes

Philippines

ultramafic
Abstract Nepenthes ultra is described from low altitude, ultramafic coastal scrub in Luzon, Philippines. It is placed in the Nepenthes alata group and is assessed as Endangered using the IUCN 2001 standard. Open cast mining and touristic development are threats to this species.

Published on 24 October 2013

\section{INTRODUCTION}

This paper forms part of our studies towards our World Monograph of Nepenthes, building on our Skeletal Revision of Nepenthes (Jebb \& Cheek 1997) and our Flora Malesiana account (Cheek \& Jebb 2001). In an earlier paper we characterised and provided a key to the Nepenthes alata Blanco group of species which is confined to the Philippines (Cheek \& Jebb 2013). In that paper we also reviewed morphological variation within Luzon of what had been considered as a single variable $N$. alata and showed that two distinct species exist, one in the northern submontane forests ( $N$. alata) and another in the southern Luzon forests, extending to the Visayas and Mindanao ( $N$. graciliflora Elmer). Among the 40 specimens of $N$. alata (in the wide sense) examined in preparing Cheek \& Jebb 2013, two anomalous specimens were found which fitted neither $N$. alata nor $N$. graciliflora in morphology. They further differ in being plants of lowland coastal scrub on ultramafic substrates. We widened our search to additional herbaria and recovered additional sheets including three more specimen numbers, which agreed in morphology and ecology with the first two specimens. Following further study of the eleven specimen sheets now available, and after linking these specimens with photographic images of plants in habitat (Nickrent et al. 2006 onwards), we here describe this material as a new species. The main diagnostic differences between $N$. alata, N. graciliflora and our new species $N$. ultra are given in Table 1 . In practice, $N$. ultra is unlikely to be confused with any other. It is the only lowland Nepenthes known in Luzon (below $400 \mathrm{~m}$ altitude), and is also the only species known to occur in ultramafic areas in Luzon.

\section{Nepenthes ultra Jebb \& Cheek, sp. nov. - Fig. 1}

Differs from $N$. alata Blanco in the upper pitchers lacking fringed wings entirely (fringed wings present below peristome at least in $N$. alata); outer pitcher surface sparsely and minutely stellate hairy, $10-15 \%$ of surface covered with red-translucent hairs $0.06-0.1 \mathrm{~mm}$ diam ( $90 \%$ of surface covered with grey hairs $0.2 \mathrm{~mm}$ diam in $N$. alata); stems glabrous or very sparsely hairy at apex (completely covered in dense long white hairs in N. alata). - Type: Ridsdale 1517 (holotype K; isotypes A, K, L, PNH n.v), Philippines, Luzon, Zambales Prov., Santa Cruz, N15²6', E12000', male inflor., 25 May 1986.

\footnotetext{
1 Royal Botanic Gardens, Kew, Richmond, Surrey, TW9 3AE, UK; corresponding author e-mail: m.cheek@kew.org.

2 National Botanic Garden, Glasnevin, Dublin 9, Republic of Ireland.
}

Etymology. The specific epithet ' 'ultra' is here used as a noun in apposition. It is a contraction of ultramafic, referring to the soils and geology to which the species appears restricted.

Terrestrial climber reaching $1.5 \mathrm{~m}$ tall, drying yellow-green. Stems with slight decurrent ridges from leaf bases, (4-)5-6 mm diam, internodes $1.5-2.7 \mathrm{~cm}$ long, axillary buds rounded, c. $1 \mathrm{~mm}$ long, inserted $6 \mathrm{~mm}$ above the axil, indumentum absent, glabrous, rarely with caducous sparse simple hairs at stem apex. Rosette stems unknown apart from a single leaf. Leaf of rosette stem leathery, elliptic 7.5 by $2 \mathrm{~cm}$, apex acute, base decurrent to petiole, veins obscure, glabrous; petiole 2 by $0.4 \mathrm{~cm}$, winged. Leaves of climbing stems spirally inserted, papery, blade narrowly oblong (10-) $12.5-23.5$ by (2.5-) $2.8-3.9 \mathrm{~cm}$, apex acute, not peltate, tendril arising abruptly, base acute to obtuse, abruptly decurrent to petiole, longitudinal nerves (2-)3(-4) pairs, conspicuous in the marginal half; pennate nerves arising at about $45^{\circ}$ from the midrib, both surfaces matt, drying dull yellow-green above, brown below, glabrous apart from scattered red-black, bun-like raised glands $0.05 \mathrm{~mm}$ diam. Petiole evenly winged along its length, $4.2-5.5(-7)$ by $(0.2-) 0.4-0.7(-1) \mathrm{cm}$, clasping the stem for $1 / 3-1 / 2$ its circumference, decurrent as low, rounded ridges. Lower pitcher $6.5 \mathrm{~cm}$ tall, $3.5 \mathrm{~cm}$ broad, ovoid in the lower half, upper cylindrical part $2 \mathrm{~cm}$ broad. Outer surface with indumentum as upper pitchers, with two fringed wings up to $4 \mathrm{~mm}$ broad running from base to apex of pitcher, fringed elements $1-4 \mathrm{~mm}$ long, c. $1.5 \mathrm{~mm}$ apart, mouth ovate, highly concave, oblique, peristome cylindrical 2-3 $\mathrm{mm}$ diam, with inconspicuous ribs $0.3 \mathrm{~mm}$ apart, inner edge with teeth $0.1 \mathrm{~mm}$ long, alternating with perforations; lid ovate, 2.6 by 2.1 $\mathrm{cm}$, apex and base rounded. Intermediate pitcher (tendril at side, uncoiled) 10 by $4 \mathrm{~cm}$, ellipsoid in the lower $5 \mathrm{~cm}$, upper half cylindrical, $2.5-2.7 \mathrm{~cm}$ diam. Outer surface with indumentum as upper pitchers, with two fringed wings $1 \mathrm{~mm}$ broad extending from apex of pitcher $1.5-3 \mathrm{~cm}$ towards base, fringed elements $2.5 \mathrm{~mm}$ long, $2-3 \mathrm{~mm}$ apart, mouth ovate, oblique, 2.7 by $2.8 \mathrm{~cm}$, column not formed, peristome cylindrical, $2 \mathrm{~mm}$ wide at front of mouth, $3.5 \mathrm{~mm}$ wide at sides, ribs inconspicuous; lid elliptic, 2.8 by $2 \mathrm{~cm}$, rounded at base and apex, lower surface of lid as upper pitcher, nectar glands c. $0.2 \mathrm{~mm}$ diam; spur c. $5 \mathrm{~mm}$ long, unbranched. Upper pitchers subcylindric, greenish white with some red markings, (11.5-)12.5-16 by $3.2-4.3 \mathrm{~cm}$, slightly wider in the basal and upper halves (subequal) gradually narrowing slightly midway to $3-3.5 \mathrm{~cm}$. Outer 


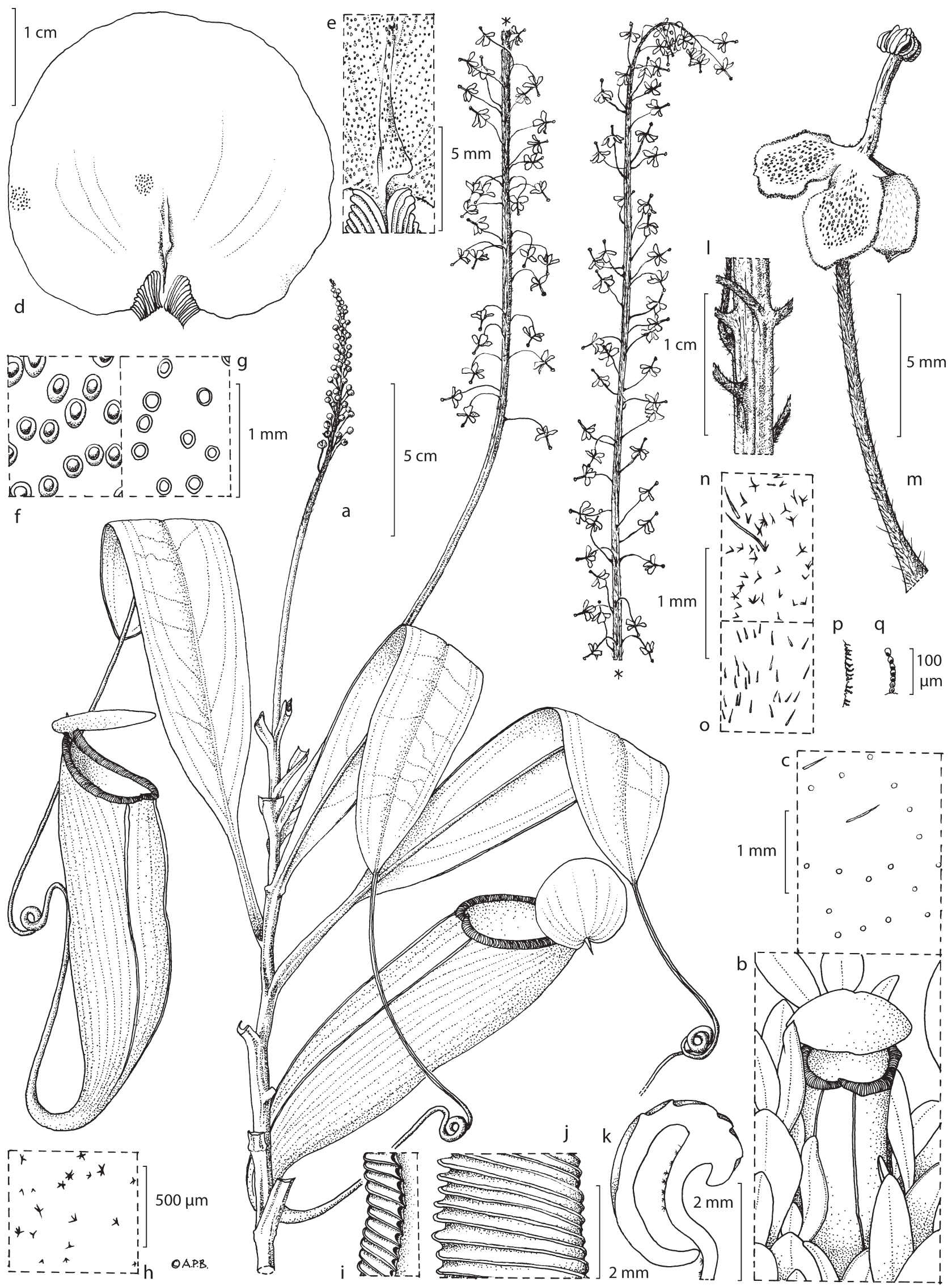

Fig. 1 Nepenthes ultra Jebb \& Cheek. a. Habit, showing upper pitchers and male inflorescence; b. upper pitcher in habitat (from photo); c. abaxial surface of leaf-blade; $d$. lower surface of pitcher lid-glands occur throughout but are shown only left of midline and at left margin; e. detail of base of lid lower surface, showing basal appendage and nectar glands; f. detail of nectar glands from margin of lid; g. detail of nectar glands from midline of lid; h. detail of stellate hairs from outer surface of pitcher; i. inner surface of peristome showing apertures; j. peristome, view from above; k. peristome, transverse section; I. rhachis of male inflorescence; $\mathrm{m}$. male flower with pedicel; $\mathrm{n}$. indumentum from inflorescence axis; $\mathrm{o}$. indumentum from adaxial tepal surface; $\mathrm{p}$. fringing moniliform hairs from tepal edge; q. moniliform hair (a, c, d, f-q: Co 3582; b: photo near Co 3567; e: Ridsdale 1517). - Scale bars: a = $5 \mathrm{~cm}$; b, i-k= $2 \mathrm{~mm}$; c, f, g, $\mathrm{n}=1 \mathrm{~mm}$; $\mathrm{d}, \mathrm{l}=1 \mathrm{~cm} ; \mathrm{e}, \mathrm{m}=5 \mathrm{~mm} ; \mathrm{h}=500 \mu \mathrm{m} ; \mathrm{p}, \mathrm{q}=100 \mu \mathrm{m}$. Drawn by Andrew Brown. 
Table 1 Major diagnostic characters separating $N$. ultra, N. alata and N. graciliflora.

\begin{tabular}{|c|c|c|c|}
\hline & N. ultra & N. alata & N. graciliflora \\
\hline Upper pitcher shape & $\begin{array}{l}\text { Subcylindric, slightly constricted in } \\
\text { middle, } \pm \text { equally wide at base and apex }\end{array}$ & $\begin{array}{l}\text { Subcylindric, slightly constricted at } \\
\text { middle, widest in basal half }\end{array}$ & $\begin{array}{l}\text { Base ventricose, abruptly constricted above } \\
\text { to a narrower subcylindric upper part }\end{array}$ \\
\hline Fringed wings in upper pitcher & $\begin{array}{l}\text { Absent, reduced to ribs along length } \\
\text { of pitcher }\end{array}$ & $\begin{array}{l}\text { Present immediately below peristome, } \\
\text { usually reduced to ribs elsewhere }\end{array}$ & $\begin{array}{l}\text { Present only on basal part; reduced to ribs } \\
\text { on upper part }\end{array}$ \\
\hline Upper pitcher outer indumentum & $\begin{array}{l}\text { Sparsely and minutely stellate hairy; } \\
\text { hairs } 3-5 \text {-armed, } 0.06-0.1(-0.15) \mathrm{mm} \\
\text { diam; arms translucent, centre red; } \\
\text { covering } 10-15 \% \text { of surface }\end{array}$ & $\begin{array}{l}\text { Densely stellate hairy; hairs } 5-8 \text {-armed } \\
\text { c. } 0.18 \mathrm{~mm} \text { diam, grey; covering }>90 \% \\
\text { of surface }\end{array}$ & $\begin{array}{l}\text { Subglabrous; stellate hairs absent; scattered } \\
\text { red, bun-like glands } 0.05 \mathrm{~mm} \text { diam and very } \\
\text { sparse simple hairs }\end{array}$ \\
\hline Stem indumentum at apex & Absent, rarely with sparse simple hairs & $\begin{array}{l}\text { Surface completely covered in dense } \\
\text { long white simple hairs }\end{array}$ & Absent apart from bun-like glands \\
\hline Range \& Ecology & $\begin{array}{l}\text { Coastal Luzon. Ultramafic scrub } \\
1.5-40(-400 ?) \text { m altitude }\end{array}$ & $\begin{array}{l}\text { Mountains of northern Luzon. } \\
\text { Submontane forest above } 500 \text { m altitude }\end{array}$ & $\begin{array}{l}\text { Mountains of southern Luzon to Mindanao. } \\
\text { Submontane forest above } 500 \text { m altitude }\end{array}$ \\
\hline
\end{tabular}

surface sparsely, minutely and inconspicuously stellate hairy; hairs covering $10-15 \%$ of the surface, evenly spread, 3-5armed, $0.06-0.1(-0.15) \mathrm{mm}$ diam, central part of hairs red, arms translucent, suberect; bushy hairs rare, c. $0.3 \mathrm{~mm}$ diam; sessile bun-shaped glands not seen; perithecoid nectar glands sparsely scattered, $0.25 \mathrm{~mm}$ diam the aperture $0.05 \mathrm{~mm}$ wide; fringed wings absent, reduced to ridges c. $1 \mathrm{~mm}$ wide running the length of the pitcher; mouth ovate $4-4.5$ by $3.5 \mathrm{~cm}$, oblique, the frontal part sometimes straight, or slightly raised, striped red; peristome rounded to flattened, $2-5 \mathrm{~mm}$ wide, widest at the sides, c. 4.5 ridges per $\mathrm{mm}$, ridges $0.1 \mathrm{~mm}$ high, inner edge lacking conspicuous teeth, outer edge not or only slightly lobed; column not developed; lid orbicular or ovate (2.6-)2.9-3(-3.2) by $(2.4-) 2.8$ by $3.5 \mathrm{~cm}$, apex rounded, truncate or emarginate, base rounded to cordate; lower surface with basal appendage slightly developed, projecting $1.5-2 \mathrm{~mm}$ from the lid as a convex protrusion from a laterally flattened midline ridge 10-12 mm long; nectar glands monomorphic, not markedly perithecoidal, with short walls, more or less uniformally dense and minute over the appendage and lower surface, 5-9 glands per $\mathrm{mm}^{2}$, orbicular to elliptic, c. $0.15 \mathrm{~mm}$ diam; upper surface of lid with indumentum as the outer pitcher. Spur inserted 1.5-2 $\mathrm{mm}$ below junction of lid and pitcher on $3 \mathrm{~mm}$ long ridge with simple hairs; spur appressed to upper pitcher, simple, stout at base tapering to acute apex, $1.75-3.5$ by $(0.25-) 0.5-0.6 \mathrm{~mm}$, densely long hairy, hairs grey, simple, subspreading $0.5 \mathrm{~mm}$ long. Male inflorescence with peduncle (8-) $16-17.5 \mathrm{~cm}$ long, $0.25-0.4 \mathrm{~cm}$ diam at base, glabrous; rachis $39-61 \mathrm{~cm}$ long, bearing c. 140 partial-peduncles scattered along its length, partial-peduncles 1-flowered, bracts absent, partial-peduncle/ pedicel $(10-) 15(-18) \mathrm{mm}$ long. Tepals 4 , obovate, $3(-3.5)$ by $2.5(-3) \mathrm{mm}$, apex rounded, margin densely hairy with moniliform hairs, upper surface with elliptic nectar glands, live colour not recorded. Androphore (2-)4 $\mathrm{mm}$ long, proximal half with scattered stellate hairs; anther head subglobose 0.6 by $1 \mathrm{~mm}$. Female inflorescence unknown except in immature and mature fruit. Infructescence peduncle $21-21.5 \mathrm{~cm}$ long, $0.3-0.5 \mathrm{~cm}$ diam at base, glabrous apart from red sessile glands; rachis 24-34 cm long, red sessile glands and sparse white appressed hairs, bearing 48-100 partial-peduncles scattered along its length, partial-peduncles 1-flowered/fruited, bracts absent, partial-peduncle/pedicel 22-28 mm long, with sparse white appressed hairs $0.25 \mathrm{~mm}$ long covering about $10 \%$ of the surface. Tepals 4 , oblong, c. 4 by $1.5 \mathrm{~mm}$. Fruit valves ligulate, c. 31 by $2 \mathrm{~mm}$, indumentum as rachis, hairs $0.1 \mathrm{~mm}$ long covering c. $20 \%$ of the surface. Seed $16 \mathrm{~mm}$ long, pale brown, seed body central, 2 by $0.4 \mathrm{~mm}$.

Distribution \& Ecology — Philippines, Luzon, lowland coastal areas with ultramafic sclerophyllous scrub; $1.5-40(-400$ ?) $\mathrm{m}$ alt.: "Ultrabasic low scrub to $1.5 \mathrm{~m}$, formation near coast, sclerophyllous and heath-like. Twining among shrubberies or forming dense mats on bare ground" (Co 3582); "Extreme ultrabasic grassland, with gallery forest along streams" (Ridsdale 1517).
"Open sea-cliffs on ultrabasic". "Open grassy area near coast, with Machaerina and patches of shrubberies. Ultramafic geology on red brown clay." (Co 3567). (Note that the $400 \mathrm{~m}$ figure is uncertain, being the altitude given on Google Earth for the inexact grid-reference given on Ridsdale 1517 as discussed under Conservation below).

Vernacular name - Inumân-kaláw (Palanan-Agtâ) fide Co 3582 and Co 3567.

Additional material. PHILIPPINES, Luzon, Zambales Prov., Santa Cruz, Ridsdale 1517 (holotype K; isotypes A, K, L, PNH n.v.), N1546', E12000', male inflor., 25 May 1986; Isabela Prov., Divilácan Municipality, Aubarede Peninsula, Lanay Spring, c. 17 km NNW of Palanan Point, Co 3582 (A n.v., BISH, L n.v., PNH n.v., US), N17016.4', E122²6.3', st. 25 May 1991; Isabela Prov., Divilácan Municipality, Aubarede Peninsula (W side facing Bicobian), Salniwan Spring, c. 17 km NNW of Palanan Point, Co 3567 (A, CAHUP, KEP, L, PNH, PUH, US all n.v.; BISH, K), N17²16.5', E122²5.6', infructescence, 25 May 1991; Isabela Prov., Palanan, Ridsdale et al. in ISU 132 (A, K), N16 ${ }^{\circ} 55^{\prime}, \mathrm{E} 122^{\circ} 30^{\prime}$, st. 24 Apr. 1991; Isabela Prov., Palanan area, Dimapnat, Ridsdale et al. in ISU $503(\mathrm{~K}), \mathrm{N} 17^{\circ} 09^{\prime}, \mathrm{E} 122^{\circ} 24^{\prime}$, immature infructescence, 13 Apr. 1992.

Photographic images studied. Luzon, Isabela Prov., Northern Sierra Madre Natural Park, Divilacan municipality, Bicobian, N17015'26", E122²6'33", st. 18 Sept. 2001 [http://131.230.176.4/imgs/pelserpb/r/Nepenthaceae_Nepenthes_alata_24689.html acc. 02/08/2012]; Aurora Prov., Baler, Dikasalarin, coordinates N1544'3", E121 $37^{\circ} 59 "$ ", st. 6 May 2011 [http://131.230.176.4/imgs/ pelserpb/r/Nepenthaceae_Nepenthes_alata_44260.html acc. 02/08/2012].

Conservation - Nepenthes ultra may be extinct at its type locality, which is its only known location on the west coast of Luzon, in Zambales Province at the Acoje Mine concession area near Santacruz. It was collected there in 1986 (Ridsdale 1517) as part of an environmental study supported by the Hilleshög enterprise. The georeference given for that specimen is approximate (whole minutes) and probably estimated from a map. When viewed in Google Earth in July 2012 several square kilometres at the location had been cleared of all vegetation, possibly for open cast mining. The Acoje mine has produced nickel, chromium and platinum group metals (http://mining.fatprophets. com.au/Member\%20Area/Product $\% 20$ Landing/Report $\% 20$ List/Report\%20Page/Article\%20Page.aspx?id=fbc9dd9158ab-4962-b29d-f711b05aba63\&product=Australasian $\% 20$ Mining\&pt=paid\&p=1, acc. 26 Sept. 2013). Ridsdale recorded the specimen as being 'common'. It would be worth seeking additional populations in adjoining, uncleared areas and, if successful, trying to protect them.

This species appears to be confined to ultramafic (also known as ultrabasic) substrates since the data for all five known specimens records this. There are two opposing conservation implications for ultramafic vegetation in Luzon. On the one hand the ultramafic scrub/grassland vegetation is unlikely to be cleared for timber (trees absent or sparse) or for agriculture (soils toxic to crops) as has happened to almost all non-ultramafic lowland vegetation on Luzon. On the other hand ultramafic substrates are often rich in metal ores of e.g. copper, cobalt or chromium, 
and so are vulnerable to mining. Fortunately, the second location, the Aubarede Peninsula and nearby Palanan in Isabela Prov. (Co 3582, 3567, Ridsdale et al. in ISU 132), is now protected as part of the northern Sierra Madre Natural Park. Since the Park is a single management unit in the sense of IUCN 2001, these records are taken as one location. The impression from Co 3582 ("twining among shrubberies or forming dense mats on bare ground") is that several individuals at least were seen here. A photo taken by Co ten years later about $2 \mathrm{~km}$ distant from his specimen (see photographic records above), appears to show the same species in the same habitat, suggesting that it may be fairly frequent within ultramafic scrub, at least at the Aubarede Peninsula/Palanan area. The Aubarede Peninsula/ Palanan area is one of only two known locations currently where the species almost certainly survives, the other, also on the east coast of Luzon, is that represented by Ridsdale et al. in ISU 503 which is about $80 \mathrm{~km}$ further south than Palanan. This seems to be just outside the Natural Park, but nonetheless in a remote and currently unthreatened area although vulnerable to degradation from tourism pressures. A second photographic record (see photographic images studied, above) very likely represents a fourth location for the species, but a specimen is needed to verify this. Photographed on 6 May 2011, in Aurora Prov., Baler, this plant is likely to survive at present, but its proximity to a private resort (Angara) suggest vulnerability to the touristic resort development along this section of the coast. Therefore, only three specimen-evidenced locations are known for $N$. ultra but it probably survives at only two of these and 'continuing decline' is indicated. We calculate the area of occupancy (IUCN 2001) of the species as $20 \mathrm{~km}^{2}$ using the preferred IUCN gridcell-size of $4 \mathrm{~km}^{2}$ (ascribing a gridcell each to the Aubarede Peninsula and Palanan sites, and one also to the locations 80 $\mathrm{km} \mathrm{S}$ of Palanan, at Aurora, and in Zambales). Therefore we here assess $N$. ultra as Endangered according to Criterion B2ab(iii) of IUCN (2001). It is to be hoped that further fieldwork will show that numerous additional individuals and protected locations exist for this species and that its conservation rating can be revised downward to a less threatened category. We suggest that more sites for the species might be found if other areas of coastal scrub are searched in Zambales, Aurora and Isabela Provinces, where most ultramafic deposits near the coast in Luzon are recorded.

\section{Variation and further work}

The female flowers of $N$. ultra remain unknown. Data on numbers of individuals and regeneration at each site, and local threats remains to be collected.

The Zambales and Isabela specimens on which this species is based, agree closely in morphology yet differ slightly in their lid shape - those of Zambales are ovate with a rounded base and apex, while those of Aurora are orbicular with either rounded or retuse apices and a cordate base. Variation also exists in the lid posture and peristome morphology. The image from Isabela, Aubarade Peninsula shows a pitcher with the lid domed, whitish green, the peristome rounded, raised at the front. In contrast the image from Aurora Prov. shows the lid with the two sides flat, raised from the midline, the peristome horizontal in front.

Acknowledgements We are grateful to Janis Shillito for typing the manuscript, Lee Davies for image digitisation, Steve Bachman for discussions on the conservation assessment, to Rogier de Kok and Peter Ashton for discussions on the Philippines, and two anonymous reviewers for constructive comments on an earlier version of the manuscript.

\section{REFERENCES}

Cheek M, Jebb M. 2001. Nepenthaceae. In: Nooteboom HP (ed), Flora Malesiana, Ser. I, 15: 1-157.

Cheek M, Jebb M. 2013. Typification and redelimitation of Nepenthes alata Blanco with notes on the N. alata group, and N. negros sp. nov. from the Philippines. Nordic Journal of Botany (published online 22 Aug. 2013, doi: 10.1111/j.1756-1051.2012.00099.x).

IUCN 2001. IUCN Red List categories and criteria: version 3.1. Prepared by the IUCN Species Survival Commission. IUCN, Gland, Switzerland and Cambridge, UK.

Jebb M, Cheek M. 1997. A skeletal revision of Nepenthes. Blumea 42: 1-106. Nickrent DL, Costea M, Barcelona JF, Pelser PB, Nixon K. 2006 onwards. Phytoimages. Available from: http://www.phytoimages.siu.edu. 